\title{
Self-Exfoliated Synthesis of Transition Metal Phosphate Nanolayers for Selective Aerobic Oxidation of Ethyl Lactate to Ethyl Pyruvate
}

\author{
Wei Zhang, Paula Oulego, Sandeep K. Sharma, Xiu-Lin Yang, Lain-Jong Li, Gadi Rothenberg, \\ and N. Raveendran Shiju*
}

Cite This: ACS Catal. 2020, 10, 3958-3967

Read Online

\section{ACCESS | Lلll Metrics \& More | 回 Article Recommendations | st Supporting Information}

ABSTRACT: Two-dimensional (2D) transition metal nanosheets are promising catalysts because of the enhanced exposure of the active species compared to their $3 \mathrm{D}$ counterparts. Here, we report a simple, scalable, and reproducible strategy to prepare $2 \mathrm{D}$ phosphate nanosheets by forming a layered structure in situ from phytic acid (PTA) and transition metal precursors. Controlled combustion of the organic groups of PTA results in interlayer carbon, which keeps the layers apart during the formation of phosphate, and the removal of this carbon results in ultrathin nanosheets with controllable layers. Applying this concept to vanadyl phosphate synthesis, we show that the method yields $2 \mathrm{D}$ ultrathin nanosheets of the orthorhombic $\beta$-form, exposing

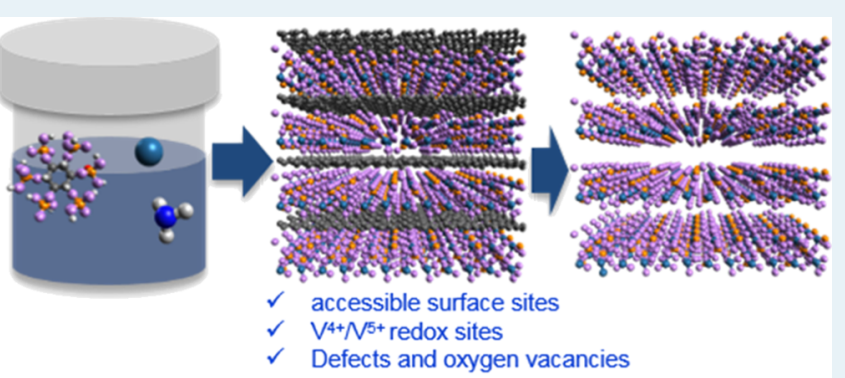

Spot on! A template-free strategy to prepare 2D phosphate nanosheets for selective aerobic oxidation abundant $\mathrm{V}^{4+} / \mathrm{V}^{5+}$ redox sites and oxygen vacancies. We demonstrate the high catalytic activity of this material in the vaporphase aerobic oxidation of ethyl lactate to ethyl pyruvate. Importantly, these $\beta$-VOPO $\mathrm{VO}_{4}$ compounds do not get hydrated, thereby reducing the competing hydrolysis reaction by water byproducts. The result has superior selectivity to ethyl pyruvate compared to analogous vanadyl phosphates. The catalysts are highly stable, maintaining a steady-state conversion of $\sim 90 \%$ (with $>80 \%$ selectivity) for at least $80 \mathrm{~h}$ on stream. This "self-exfoliated" synthesis protocol opens opportunities for preparing structurally diverse metal phosphates for catalysis and other applications.

KEYWORDS: metal phosphate, $\beta$-phase, ultrathin nanosheets, heterogeneous catalysis, aerobic oxidation, lactic acid

\section{INTRODUCTION}

Ultrathin two-dimensional (2D) materials are attracting increased attention for several applications, thanks to their distinctive electronic, optical, semiconducting, and catalytic properties. $^{1,2}$ Single- or few-layer 2D sheets expose more interior atoms than their bulk counterparts, with abundant surface-active sites and vacancy defects. ${ }^{3,4}$ The $2 \mathrm{D}$ confinement effect also can shorten mass and heat diffusion pathways. ${ }^{5}$ This makes them promising candidates for designing efficient heterogeneous catalysts.

The main state-of-the-art methods for preparing few-layer nanosheets are gas/liquid exfoliation, ion intercalation, or mechanical cleavage. ${ }^{7}$ These top-down approaches are suitable for stacked materials with interplanar van der Waals interactions, such as graphene, boron nitride, and carbon nitride. $^{8}$ Synthesizing 2D nanosheets from nonlayered materials is much more difficult. ${ }^{9}$ It requires harsh conditions and gives varied thicknesses and low yields. ${ }^{10}$ Alternatively, 2D nonlayered nanosheets can be produced through templateassisted synthesis, ${ }^{11,12}$ surfactant self-assembly, ${ }^{13,14}$ oriented attachment growth, ${ }^{15}$ and inorganic-organic lamellar hybrid intermediates. ${ }^{16}$ Still, making high-quality ultrathin nanosheets of nonlayered inorganic materials remains a challenge. ${ }^{17,18}$
For example, vanadium phosphates (VPOs) are composed of alternating vanadium octahedra $\left(\mathrm{VO}_{6}\right)$ and phosphate tetrahedra $\left(\mathrm{PO}_{4}\right){ }^{19}$ Several crystal structures in different oxidation states are known, such as $\mathrm{V}^{5+}$ vanadyl phosphate (i.e., $\alpha_{\mathrm{I}^{-}}, \alpha_{\mathrm{II}}, \beta-, \omega-, \delta-, \varepsilon$-, and $\left.\gamma-\mathrm{V}^{\mathrm{V}} \mathrm{OPO}_{4}\right)$ and $\mathrm{V}^{4+}$ vanadyl pyrophosphate $\left[\left(\mathrm{V}^{\mathrm{IV}} \mathrm{O}\right)_{2} \mathrm{P}_{2} \mathrm{O}_{7}\right]^{20-24}$ The $\beta$-phase is thermodynamically the most stable. ${ }^{25}$ However, because this compact structure has fewer accessible active sites, its catalytic activity is low. ${ }^{26}$ We hypothesized that this problem could be avoided by structuring $\beta$-VOPO ${ }_{4}$ as thin nanosheets, thus exposing more surface $\mathrm{V}^{4+} / \mathrm{V}^{5+}$ redox couples. ${ }^{27} \mathrm{VOPO}_{4}$ nanosheets are currently prepared by intercalation-exfoliation of bulk $\alpha$ VOPO $_{4} \cdot 2 \mathrm{H}_{2} \mathrm{O}$, exploiting the weak hydrogen bonds between layers. ${ }^{28}$ However, unlike layered $\alpha-\mathrm{VOPO}_{4}$, the 3D network of the nonlayered $\beta$-phase is unsuitable for this method, giving no control over the number of layers.

Received: October 15, 2019

Revised: February 17, 2020

Published: February 19, 2020 


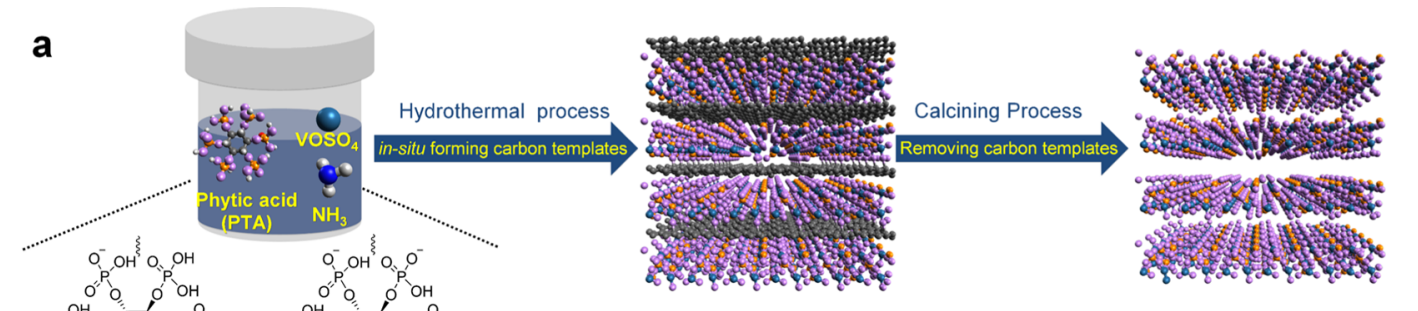

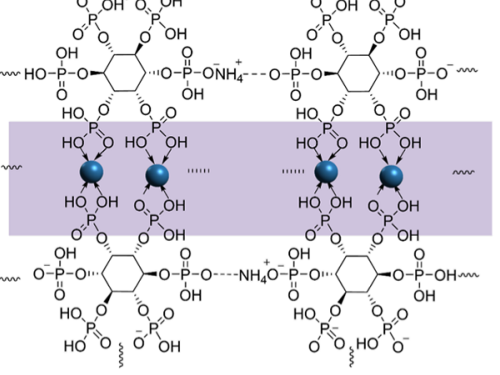

Vanadium-PTA coordination

b

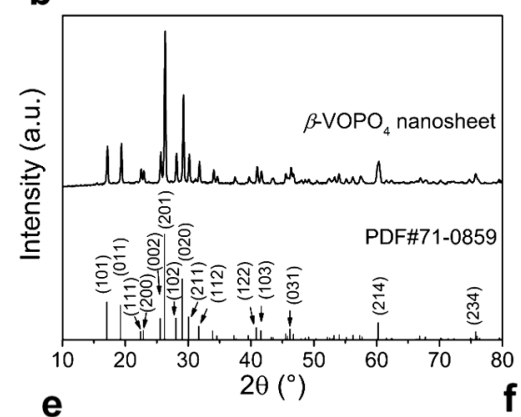

e

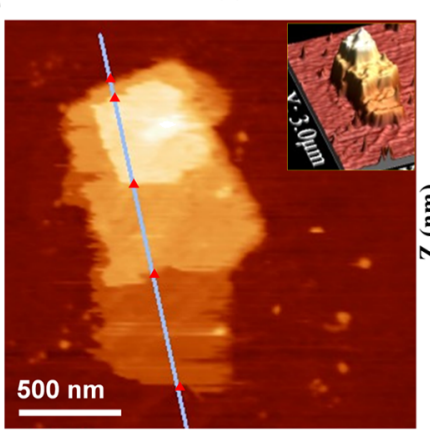

h

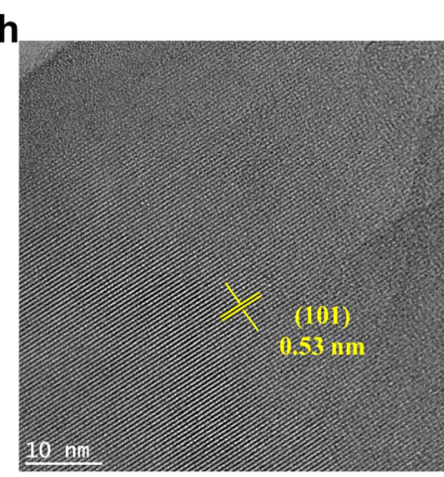

i

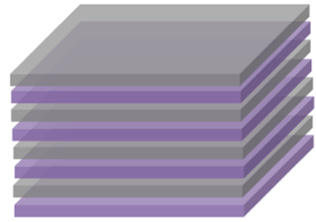

VOP@C

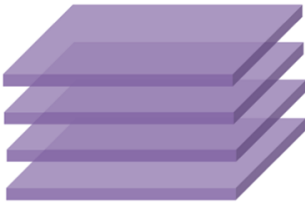

2D $\beta-\mathrm{VOPO}_{4}$ nanosheets

\section{d}

C
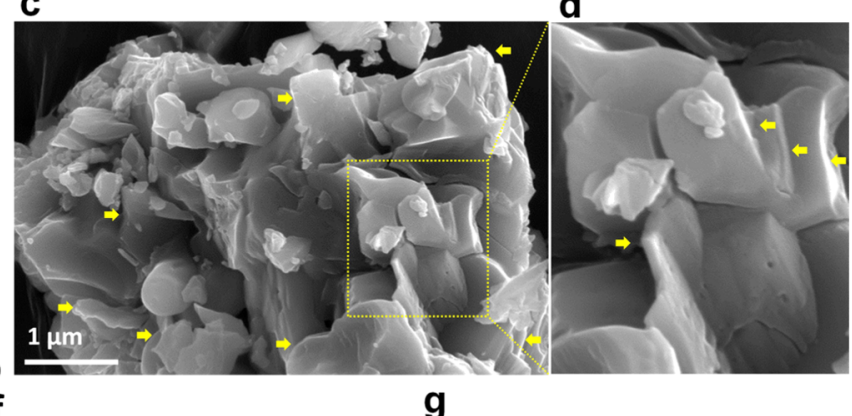

g
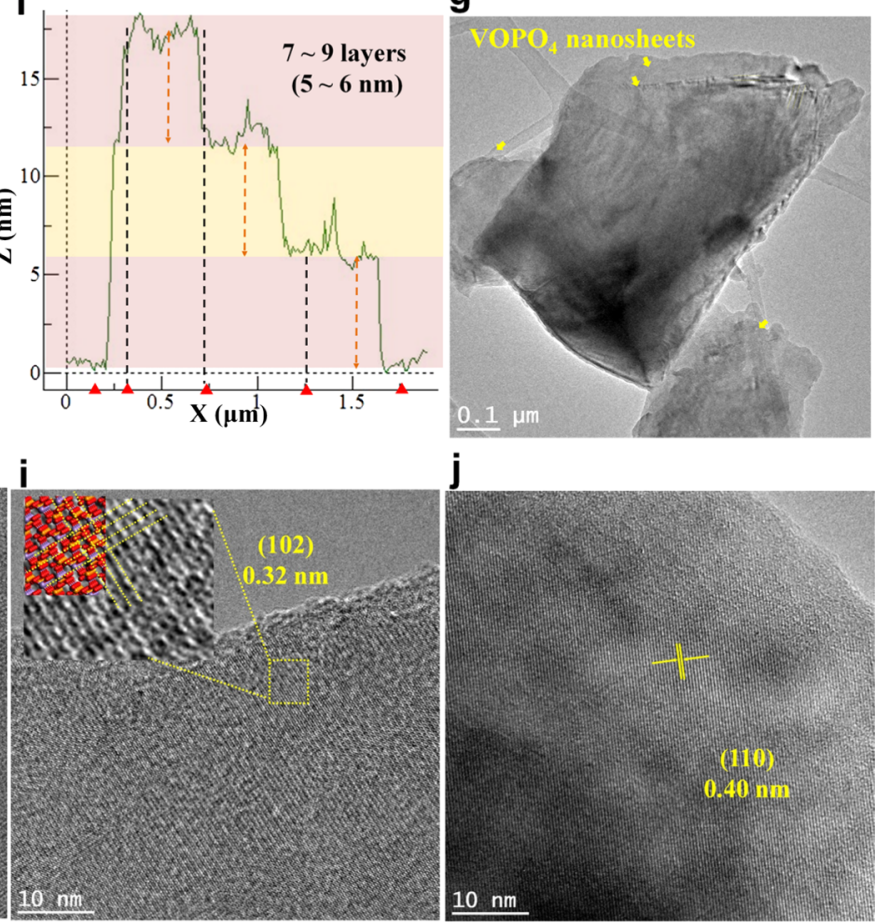

Figure 1. (a) Schematic summary of the synthesis procedure for $2 \mathrm{D} \beta$-VOPO 4 nanosheets. (b) X-ray diffraction pattern of $2 \mathrm{D} \beta$-VOPO nanosheets (the inset shows the model of layered $\beta$-VOPO $\left.{ }_{4}\right)$; (c,d) SEM images of $\beta$-VOPO flakes stacked by the layered structure; (e) AFM image of few-layer $\beta$-VOPO 4 nanosheets (inset: the corresponding 3D demonstration); (f) thickness of nanosheets derived from AFM measurement; $(\mathrm{g})$ representative TEM images of $\beta$-VOPO $\mathrm{VO}_{4}$ nanosheets; and $(\mathrm{h}-\mathrm{j})$ magnified HRTEM images of $\beta$-VOPO $\mathrm{VO}_{4}$ nanosheets taken along [101], [102], and [110] directions.

Here, we report a new template-free and scalable method for preparing $2 \mathrm{D} \beta$ - $\mathrm{VOPO}_{4}$ ultrathin nanosheets with controlled layers. These sheets are made by self-assembly of vanadyl sulfate $\left(\mathrm{VOSO}_{4}\right)$ and phytic acid (PTA) precursors, which are abundant and inexpensive; vanadyl sulfate is a byproduct of crude oil refining, and PTA is a renewable plant-based acid. The PTA molecules are the key to this synthesis: (i) they react with $\mathrm{VOSO}_{4}$ as strong chelating agents, suppressing the 

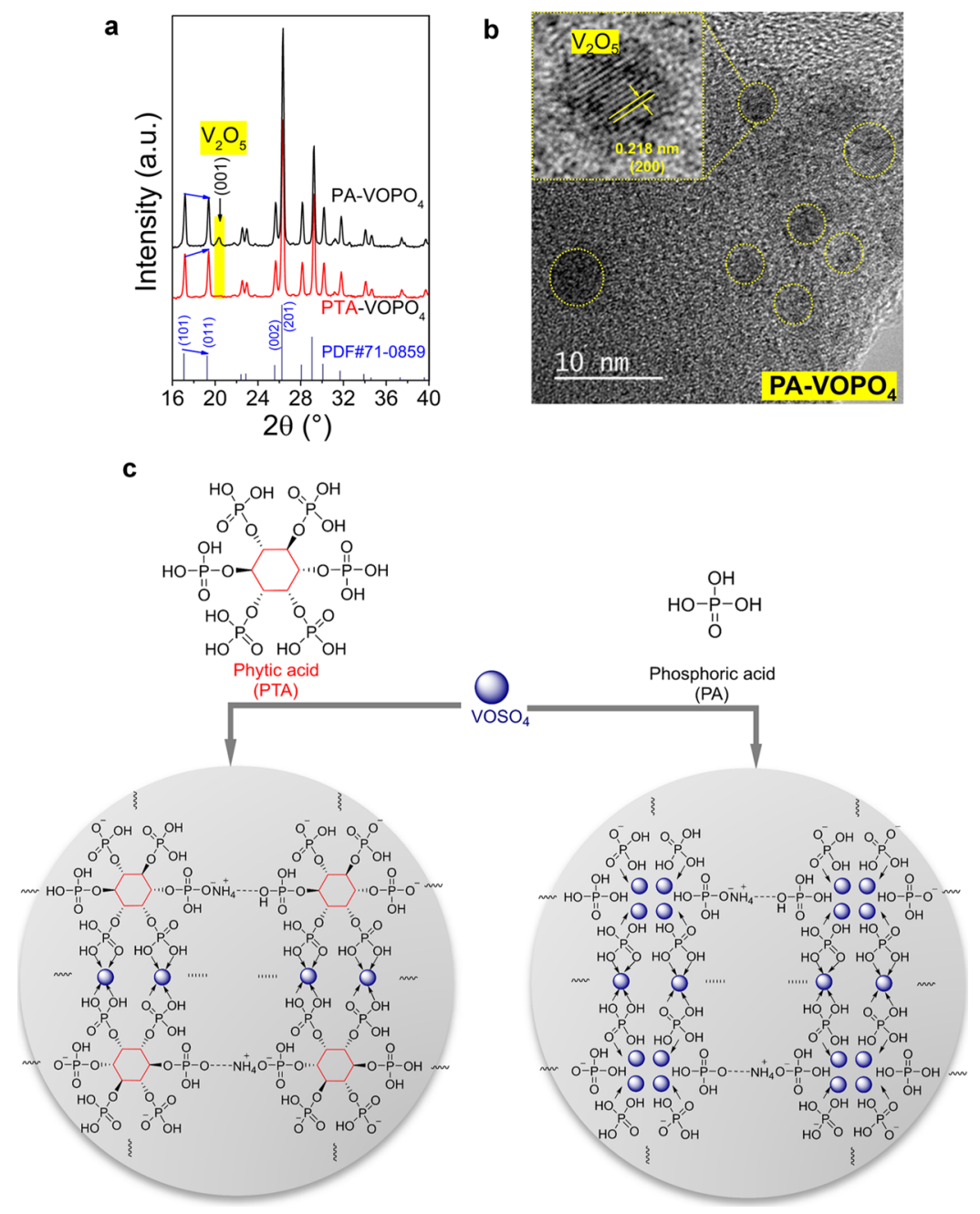

Figure 2. (a) Comparison of the X-ray diffraction patterns of two $\beta$ - $\mathrm{VOPO}_{4}$ catalysts: phytic acid-derived $\mathrm{VOPO}_{4}$ nanosheets $\left(\mathrm{PTA}^{-\mathrm{VOPO}}\right)_{4}$ and the corresponding phosphoric acid-derived $\mathrm{VOPO}_{4}\left(\mathrm{PA}-\mathrm{VOPO}_{4}\right)$; (b) magnified HRTEM images of PA-VOPO , and the inset shows the $\mathrm{V}_{2} \mathrm{O}_{5}$ nanoparticles with the (200) lattice space. (c) Schematic of the self-assembly process of $\mathrm{VOSO}_{4}$ and P precursors: PTA and phosphoric acid (PA).

agglomeration of vanadium species, and (ii) they form carbon layers between the vanadium-phosphate complexes from the cyclohexane rings during the hydrothermal process. Subsequent pyrolysis removes the PTA, creating more accessible surface and increasing the number of $\mathrm{V}^{4+} / \mathrm{V}^{5+}$ redox sites and oxygen vacancies. This self-exfoliating concept is also general, giving access to various thin transition metal phosphate sheets. We used this method to make active and selective catalysts from inactive forms of phosphates by structuring them as thin nanosheets, thereby exposing more surface active species. The resulting $2 \mathrm{D} \beta-\mathrm{VOPO}_{4}$ ultrathin sheets are excellent catalysts for the vapor-phase air oxidation of ethyl lactate to ethyl pyruvate (Figure S1, see the Supporting Information for full experimental details).

\section{RESULTS AND DISCUSSION}

Synthesis and Characterization of $\boldsymbol{\beta}$-VOPO $\mathrm{VO}_{4}$ Nanosheets. Figure 1a illustrates the synthesis strategy for $2 \mathrm{D} \beta$ $\mathrm{VOPO}_{4}$ ultrathin sheets. In the first step of this simple two-step process, PTA and $\mathrm{VOSO}_{4}$ are dissolved in aqueous solutions, separately. After mixing the two solutions, the vanadium-PTA coordination precursors are formed by the self-assembly of vanadyl ions and PTA. Subsequently, ammonia was added to the mixture, adjusting the $\mathrm{pH}$ to $\sim 6$. Adding ammonia accelerates the complexation and helps to form cross-linked networks by surrounding the vanadium-PTA micelles. The amorphous mixture is then subjected to a hydrothermal treatment (Figure S2). Then, the cyclohexane part of PTA is carbonized, forming VOP@C hybrids. Note that the growth of carbon was restricted between the interlayers of VOP-PTA hybrids, forming extended $2 \mathrm{D}$ carbon layers. In the second step, the in situ-formed carbon templates were removed by heat treatment at $550{ }^{\circ} \mathrm{C}$, yielding $2 \mathrm{D} \beta-\mathrm{VOPO}_{4}$ nanosheets.

Powder X-ray diffraction analysis confirmed the formation of the pure orthorhombic $\beta-\mathrm{VOPO}_{4}$ phase (Figure $1 \mathrm{~b}$, cf. PDF\#71-0859). Scanning electron microscopy (SEM) images show the stacked $2 \mathrm{D}$ plates with a smooth surface, shaped edges and corners, indicating a typical lamellar layered morphology (Figure 1c,d). Analysis of the sample by atomic force microscopy (AFM) (Figures 1e and S3) and the corresponding AFM height profile (Figure 1f) indicate that the $\mathrm{VOPO}_{4}$ samples comprise three stacks (see the inset in Figure 1e), each with the same average thickness of $\sim 6 \mathrm{~nm}$. This confirms that we successfully synthesized the $\beta-\mathrm{VOPO}_{4}$ nanosheets with a controlled thickness of about $7-8$ atomic monolayers. The ultrathin and nearly transparent features of $\mathrm{VOPO}_{4}$ nanosheets are also shown by transmission electron microscopy (TEM) (Figure 1g), upholding the AFM results. 
Moreover, the high-resolution TEM (HRTEM) images show the clear lattice fringes with interplanar distances of $0.53,0.32$, and $0.40 \mathrm{~nm}$ (Figure $1 \mathrm{~h}-\mathrm{j}$ ), which can be assigned to the (101), (102), and (110) planes of the $\beta-\mathrm{VOPO}_{4}$ structure, respectively.

We hypothesized that PTA plays a key role in the formation of $2 \mathrm{D} \beta-\mathrm{VOPO}_{4}$ nanosheets. To test this, we ran a control experiment, where instead of PTA, we used phosphoric acid $\left(\mathrm{H}_{3} \mathrm{PO}_{4}\right)$ as the $\mathrm{P}$ precursor (all other conditions were identical). The resulting $\mathrm{VOPO}_{4}$ material is denoted as PA$\mathrm{VOPO}_{4}$. As shown in Figure 2a, the XRD pattern of PA$\mathrm{VOPO}_{4}$ is almost identical to that of the PTA-derived $\mathrm{VOPO}_{4}$ nanosheets (denoted as $\mathrm{PTA}-\mathrm{VOPO}_{4}$ ), yielding a typical $\beta$ structure. Unlike layered $\alpha-\mathrm{VOPO}_{4}$ with $2 \mathrm{D}$ anisotropic growth (the adjacent layers are connected with weak van der Waals force), ${ }^{28}$ diffraction peaks do not shift in the $\beta$-phase. ${ }^{29}$ However, the ratios of both $(011) /(101)$ and $(002) /(201)$ planes in $\mathrm{PTA}-\mathrm{VOPO}_{4}$ are higher than those of $\mathrm{PA}-\mathrm{VOPO}_{4}$ (Figures 2a and S4), probably because of the lamellar layered structure of $\mathrm{PTA}-\mathrm{VOPO}_{4}$.

However, an additional peak appeared at $20.3^{\circ}$ in PA$\mathrm{VOPO}_{4}$, which belongs to crystalline $\mathrm{V}_{2} \mathrm{O}_{5}$. This indicates that some of the vanadyl species are aggregated into $\mathrm{V}_{2} \mathrm{O}_{5}$. Indeed, a representative HRTEM image of $\mathrm{PA}-\mathrm{VOPO}_{4}$ (Figure 2b) confirmed that the $\mathrm{V}_{2} \mathrm{O}_{5}$ nanocrystallites are dispersed on the $\mathrm{VOPO}_{4}$ matrix. The inset clearly shows lattice fringes of 0.218 $\mathrm{nm}$, corresponding to the (200) lattice space of crystalline $\mathrm{V}_{2} \mathrm{O}_{5}$. The chemical mapping by energy-dispersive $\mathrm{X}$-ray (EDX) spectroscopy showed that the mean atomic $\mathrm{V} / \mathrm{P}$ ratio of surface PTA-VOPO ${ }_{4}$ is 0.9 (Table $\mathrm{S} 1$ ), much lower than that of $\mathrm{PA}-\mathrm{VOPO}_{4}(1.41$, see Table S2), indicating the aggregation of vanadia species on the surface of $\mathrm{PA}-\mathrm{VOPO}_{4}$.

Both PTA and phosphoric acid are strong chelating agents and coordinate to $\mathrm{VOSO}_{4}$. As shown in Figure 2c, PTA comprises six phosphoric acids attached to a cyclohexane ring. Unlike plain phosphoric acid, the steric hindrance of PTA prevents aggregation during the co-assembly process. Moreover, during the hydrothermal treatment, the cyclohexane segments of PTAs are carbonized into a carbon framework, suppressing the agglomeration of vanadium species to $\mathrm{V}_{2} \mathrm{O}_{5}$. Indeed, after the hydrothermal treatment, the nitrogen sorption isotherm of PTA-derived VOP (PTA-VOP ${ }_{\mathrm{HT}}$ ) showed increased $\mathrm{N}_{2}$ uptake in the low relative pressure $(P /$ $\left.P_{0}<0.1\right)$ and a hysteresis loop in the region of $P / P_{0}>0.4$, suggesting the formation of a carbon rich in micropores and mesopores (Figure S5a). In contrast, the PA-VOP $\mathrm{HT}_{\mathrm{HT}}$ gave negligible $\mathrm{N}_{2}$ adsorption. Subsequent calcination removes the carbon, giving $\mathrm{PTA}-\mathrm{VOPO}_{4}$, showing a steep rise in the range of $P / P_{0}>0.9$ (Figure $\mathrm{S} 5 \mathrm{~b}$ ), which can be assigned to the interlayer voids. We also prepared $\mathrm{PA}-\mathrm{VOPO}_{4}$ samples with different $\mathrm{VOSO}_{4} / \mathrm{PA}$ molar ratios (0.5 and 0.8) under otherwise identical conditions, trying to avoid the formation of crystalline $\mathrm{V}_{2} \mathrm{O}_{5}$. As is evident from the XRD patterns in Figure $\mathrm{S} 6$ in the Supporting Information, crystalline $\mathrm{V}_{2} \mathrm{O}_{5}$ was present in these samples, further verifying the vital role of the PTA precursor. We conclude that owing to the confined carbonization of PTA, the formed carbon acts as an in situ template, giving the desired few-layer nanosheets. Control experiments wherein the vanadium-PTA complex was directly calcined without any hydrothermal treatment led to the formation of amorphous VPO (Figure S7), upholding our conclusion.
We then studied the catalytic performance of these $\beta$ $\mathrm{VOPO}_{4}$ materials in the vapor-phase oxidative dehydrogenation of ethyl lactate with air to give ethyl pyruvate in a fixedbed reactor (eq 1). Lactates are biomass-derived "platform

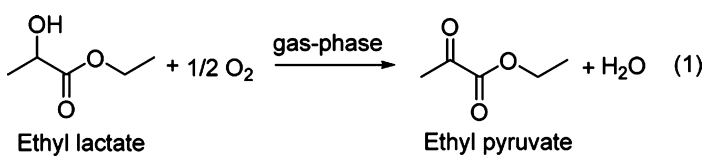

molecules, ${ }^{30}$ and direct aerobic oxidation of lactate is a sustainable route to biobased pyruvate, an important intermediate in the food, cosmetics, pharmaceutical, and agrochemical sectors. ${ }^{31,32}$ Previously, we showed that aerobic oxidation of ethyl lactate requires relatively high temperatures. However, the pyruvate is easily overoxidized on the catalyst surface at such high temperatures, lowering the product selectivity. ${ }^{33}$ A series of control experiments confirmed that the reaction is in the kinetic regime, with no mass-transfer limitations. Then, we measured the selectivity to ethyl pyruvate against ethyl lactate conversion over phytic acid-derived $\mathrm{VOPO}_{4}$ nanosheets $\left(\mathrm{PTA}-\mathrm{VOPO}_{4}\right)$ and phosphoric acidderived $3 \mathrm{D} \mathrm{VOPO}_{4}$ nanoparticles $\left(\mathrm{PA}-\mathrm{VOPO}_{4}\right)$ (Figure $3 \mathrm{a}$ ).
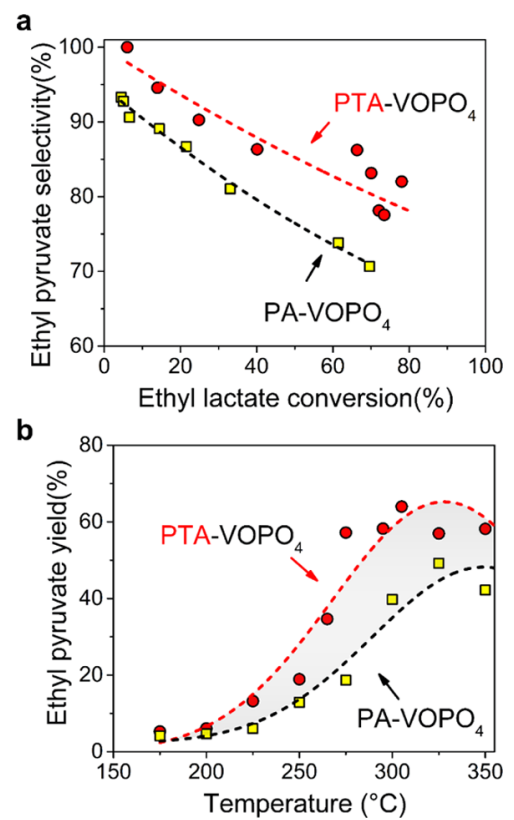

Figure 3. Vapor-phase oxidative dehydrogenation of ethyl lactate with air to give ethyl pyruvate over various $\beta$-VOPO 4 catalysts: (a) Selectivity to ethyl pyruvate plotted against conversion over PTA$\mathrm{VOPO}_{4}$ and $\mathrm{PA}-\mathrm{VOPO}_{4}$. Reaction conditions: ethyl lactate WHSV = $6.25 \mathrm{~h}^{-1}$, air carrier flow rate $=2.25 \mathrm{~L} / \mathrm{h}$; (b) corresponding temperature-resolved yield profile of ethyl pyruvate. All data were taken after $2 \mathrm{~h}$ on stream.

PTA-VOPO ${ }_{4}$ outperformed $\mathrm{PA}-\mathrm{VOPO}_{4}$ under identical reaction conditions. At the same conversion of ethyl lactate, $\mathrm{PTA}-\mathrm{VOPO}_{4}$ is more selective for ethyl pyruvate than PA$\mathrm{VOPO}_{4}$. The ethyl pyruvate yield at different reaction temperatures was much higher over PTA-VOPO ${ }_{4}$ nanosheets (Figure $3 \mathrm{~b}$ ), confirming the enhanced catalytic activity. Previously, we demonstrated that this reaction is kinetically favored in the presence of isolated amorphous vanadium oxide sites, while crystalline $\mathrm{V}_{2} \mathrm{O}_{5}$ can catalyze this reaction but not selective. ${ }^{34,35} \mathrm{PA}-\mathrm{VOPO}_{4}$ features well-dispersed $\mathrm{V}_{2} \mathrm{O}_{5}$ nano- 


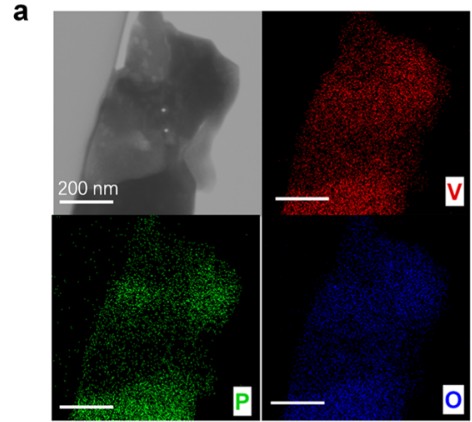

C
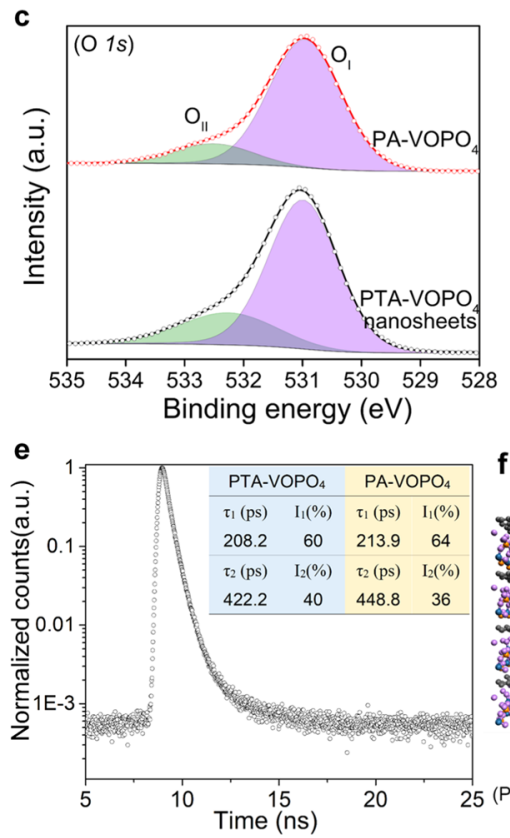

f

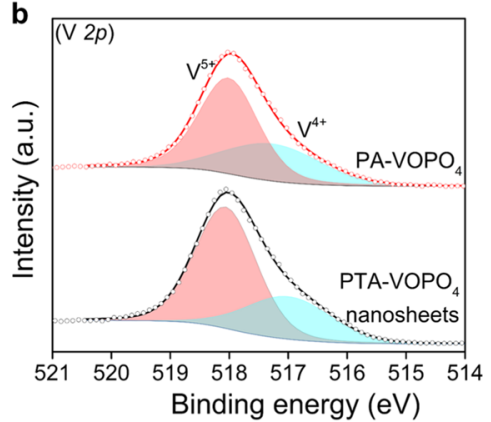

d

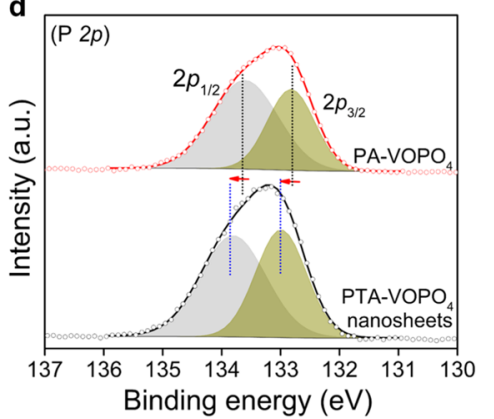

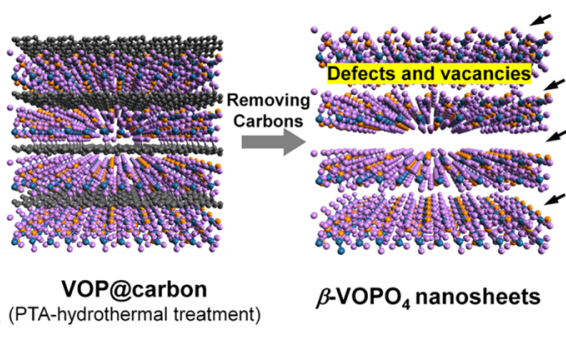

Figure 4. (a) STEM image and corresponding elemental mappings of V, P, and O of PTA-VOPO ${ }_{4}$ nanosheets. XPS studies showing high-

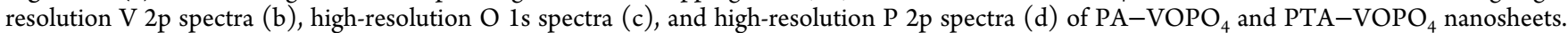
(e) PALS spectra of $\mathrm{PTA}_{-} \mathrm{VOPO}_{4}$ nanosheets (the inset shows the positron annihilation lifetimes and the corresponding intensities in PA$\mathrm{VOPO}_{4}$ and $\mathrm{PTA}-\mathrm{VOPO}_{4}$ nanosheets, respectively). (f) Schematic diagram of defects and vacancies, originating from the removal of carbon layers, in $\mathrm{PTA}-\mathrm{VOPO}_{4}$ nanosheets.

crystals on the surface, yet its catalytic activity and selectively are lower compared to that of $\mathrm{PTA}-\mathrm{VOPO}_{4}$. This is probably because the surface $\mathrm{V}^{4+} / \mathrm{V}^{5+}$ active sites and oxygen vacancies of $\mathrm{PA}-\mathrm{VOPO}_{4}$ are less accessible than those in $\mathrm{PTA}-\mathrm{VOPO}_{4}$. We then reasoned that the reactivity enhancement on PTA$\mathrm{VOPO}_{4}$ is due to the exposed $\mathrm{V}^{4+} / \mathrm{V}^{5+}$ redox sites and oxygen vacancies.

Factors Governing Activity and Selectivity. We further characterized the $\beta$-VOPO 4 sheets to understand this enhanced activity. The full X-ray photoelectron spectroscopy (XPS) survey spectra showed V, P, and O in all samples (Figure S8), in accordance with elemental mapping from highangle annular dark-field scanning TEM (HAADF-STEM) analysis (Figures $4 a$ and S9). As shown in Figure 4b, the spectra of $\mathrm{V} 2 \mathrm{p}$ can be deconvoluted into two peaks centered at 517.2 and $518.0 \mathrm{eV}$, which are associated with $\mathrm{V}^{4+}$ and $\mathrm{V}^{5+}$ species, respectively. The $\mathrm{PTA}-\mathrm{VOPO}_{4}$ nanosheets gave a much higher $\mathrm{V}^{4+} /\left(\mathrm{V}^{4+}+\mathrm{V}^{5+}\right)$ ratio of $40 \%$, in comparison to $30 \%$ in the bulk $\mathrm{PA}-\mathrm{VOPO}_{4}$ material. Thus, ultrathin nanosheets expose more accessible surface sites, thereby increasing the number of surface $\mathrm{V}^{4+}$ species. The enhanced catalytic activity can be assigned to the increased $\mathrm{V}^{4+} / \mathrm{V}^{5+}$ redox active sites of $\beta-\mathrm{VOPO}_{4}$ nanosheets. ${ }^{36}$ From redox perspectives, introducing $\mathrm{V}^{4+}$ into $\beta$ - $\mathrm{VOPO}_{4}$ nanosheets increases the number of defects and oxygen vacancies. Elsewhere, we have reported that the oxidation of ethyl lactate follows a Mars-van Krevelen mechanism: ethyl lactate adsorbed on the catalytic surface is oxidized by the lattice oxygen, and then, the resultant oxygen vacancies are replenished by gas-phase oxygen during the oxidation reaction. ${ }^{33}$ Thus, both surface lattice oxygens and oxygen vacancies play key roles in aerobic oxidation of ethyl lactate to ethyl pyruvate. These two species can be roughly estimated from the O 1s XPS spectrum (Figure 4c): the peak at $\sim 532.5$ $\mathrm{eV}$ can be attributed to the lattice oxygen $\left(\mathrm{O}_{\mathrm{I}}\right)$ and the peak at $\sim 531.0 \mathrm{eV}$ can be attributed to the adsorbed oxygen species at the vacancy sites $\left(\mathrm{O}_{\mathrm{II}}\right) .{ }^{4}$ The $\mathrm{O}_{\mathrm{I}}$ peak has a larger area for the PTA- $\mathrm{VOPO}_{4}$ nanosheets than $\mathrm{PA}-\mathrm{VOPO}_{4}$, indicating that the former exposes more lattice oxygen atoms. Additionally, $\mathrm{O}_{\mathrm{II}}$ oxygens can enhance the mobility of oxygen species; they are more easily reduced and favorable for the oxidation reaction. PTA-VOPO 4 has a higher $\mathrm{O}_{\text {II }} /\left(\mathrm{O}_{\mathrm{I}}+\mathrm{O}_{\text {II }}\right)$ ratio, indicating abundant structural defects and oxygen vacancies. Moreover, as the structural defects and oxygen vacancies decrease the electron charge density around phosphorus of

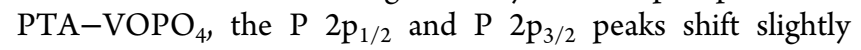


a $\mathrm{NiPO}_{4}$

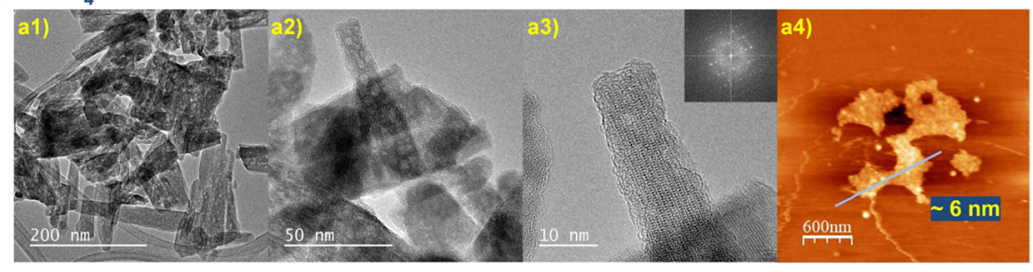

b $\mathrm{CoPO}_{4}$

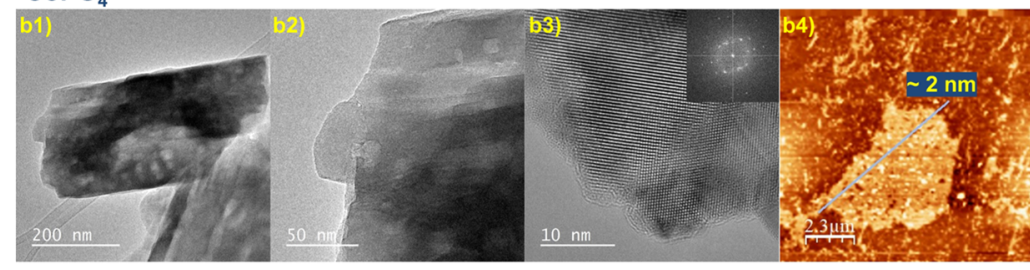

C $\mathrm{FePO}_{4}$

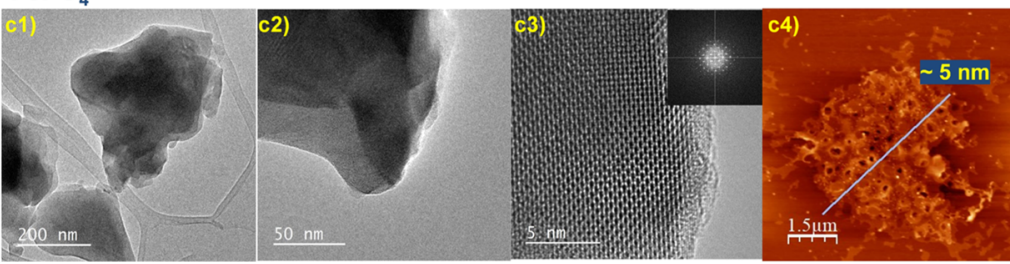

Figure 5. Morphological and microstructural characterization of various PTA-derived metal-phosphate nanosheets $(\mathrm{a}-\mathrm{c})$; $\mathrm{NiPO}_{4}$ nanosheets: $(\mathrm{a} 1-$ a3) TEM images and (a4) AFM image; $\mathrm{CoPO}_{4}$ nanosheets: (b1-b3) TEM images and (b4) AFM image; FePO ${ }_{4}$ nanosheets: (c1-c3) TEM images and (c4) AFM image. Note: the corresponding height profiles of phosphate nanosheets are shown in Figure S11, which were derived from AFM measurement.
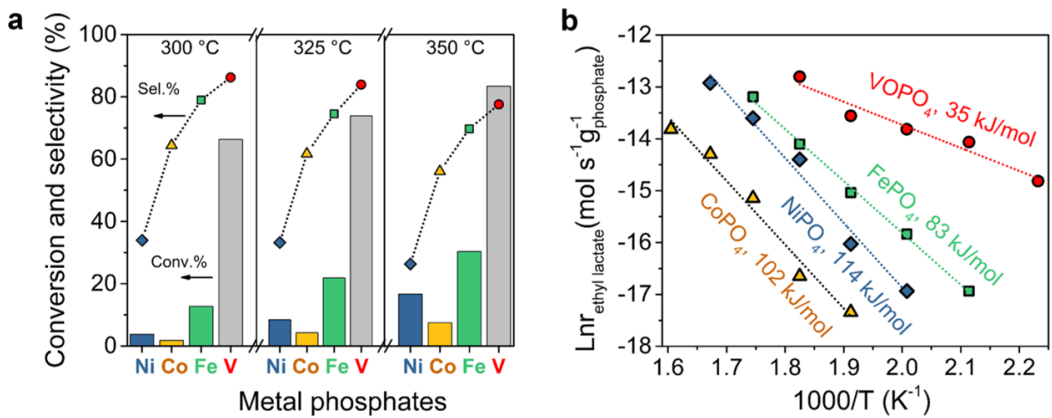

Figure 6. (a) Comparisons of ethyl lactate conversion and ethyl pyruvate selectivity over various PTA-derived metal phosphate nanosheets: $\mathrm{VOPO}_{4}, \mathrm{FePO}_{4}, \mathrm{CoPO}_{4}$, and $\mathrm{NiPO}_{4}$. Reaction conditions: ethyl lactate WHSV $=8 \mathrm{~h}^{-1}$, air flow rate $=2.25 \mathrm{~L} / \mathrm{h}$, and reaction temperature: 300 , 325 , and $350^{\circ} \mathrm{C}$. (b) Arrhenius plots for steady-state ethyl lactate consumption rate over various phosphate catalysts, and the apparent activation energy $\left(E_{\mathrm{a}}\right)$ was measured at a series of temperatures below $15 \%$ ethyl lactate conversion.

toward a higher binding energy in comparison with PA$\mathrm{VOPO}_{4}$ (Figure 4d). ${ }^{37}$

Further information on the structural defects was obtained from positron annihilation lifetime spectroscopy (PALS). Figure $4 \mathrm{e}$ shows a typical PALS spectrum of PTA-VOPO All the PALS spectra could be fitted to two positron lifetime components with a reasonable variance of fit (1.0-1.1). The first positron lifetime $\left(\tau_{1}\right)$ in the range of $\sim 208-240$ ps is attributed to positron annihilation in the bulk of the materials (see the inset in Figure 4e). The longer lifetime $\left(\tau_{2}\right)$ in the range of $\sim 422-478$ ps indicates the presence of larger-size defects, that is, vacancy clusters present either in the bulk or at the grain boundaries of the samples. The $\tau_{1}$ values of PTA$\mathrm{VOPO}_{4}$ and $\mathrm{PA}-\mathrm{VOPO}_{4}$ are nearly the same, showing the identical lattice structure. The intensity corresponding to larger components $\left(I_{2}\right)$ is higher (40\%) for nanosheets compared to that of bulk $\mathrm{PA}-\mathrm{VOPO}_{4}(36 \%)$, suggesting more vacancy defects for PTA-VOPO 4 nanosheets. Positrons trapped at the defect sites predominantly annihilate with the surrounding elements and hence provide information about the chemical surrounding. They are efficiently trapped either at negatively charged or neutral open volume defects such as vacancy clusters. According to the crystal structure of the samples, cation vacancy defects (e.g., V or P based vacancy defects) are surrounded by oxygen atoms. Figure S10 shows the ratio curves of these samples with respect to a reference $\mathrm{Si}$, in which the peak at $P_{\mathrm{L}} \approx 10 \times 10^{-3} m_{o} c$ indicates the annihilation with the surrounding oxygen atoms at the defect sites. The corresponding peak intensity of $\mathrm{PTA}-\mathrm{VOPO}_{4}$ is higher than that of $\mathrm{PA}-\mathrm{VOPO}_{4}$, indicating that the defects present in the nanosheets have more $\mathrm{O}$ atoms in the surrounding lattice sites. Thus, our ultrathin $\mathrm{VOPO}_{4}$ nanosheets expose more lattice oxygen and oxygen vacancies (Figure $4 \mathrm{f}$ ), which can explain their high catalytic activity. 

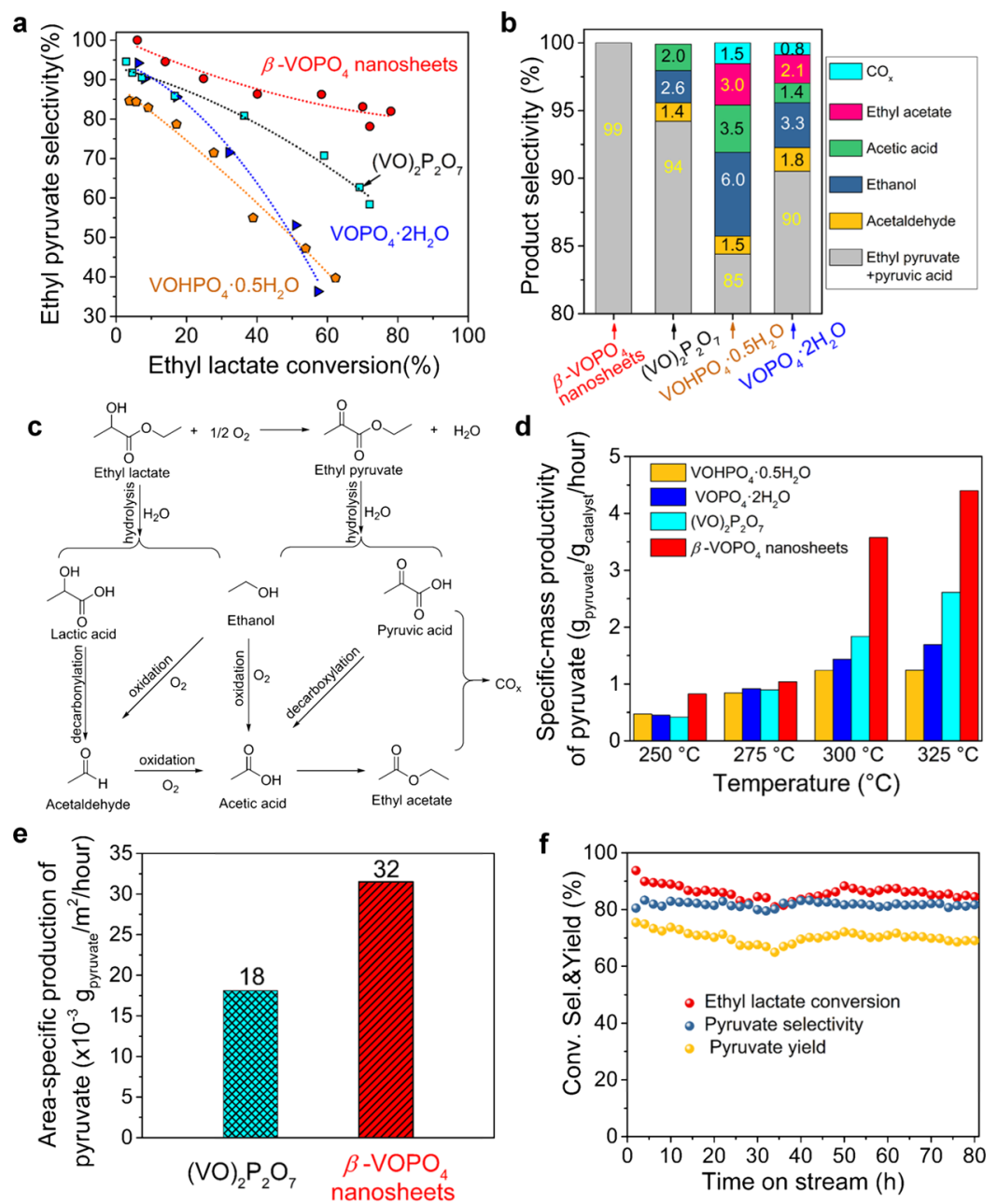

Figure 7. (a) Selectivity to ethyl pyruvate plotted against conversion for different VPO catalysts: $2 \mathrm{D} \beta$-VOPO ${ }_{4}$ nanosheets, $(\mathrm{VO})_{2} \mathrm{P}_{2} \mathrm{O}_{7}, \mathrm{VOHPO}$. $0.5 \mathrm{H}_{2} \mathrm{O}$, and $\mathrm{VOPO}_{4} \cdot 2 \mathrm{H}_{2} \mathrm{O}$. (b) Comparison of the selectivity of various products at an ethyl lactate conversion of $\sim 6 \%(\beta$-VOPO nanosheets: $6.0 \%$, $(\mathrm{VO})_{2} \mathrm{P}_{2} \mathrm{O}_{7}: 6.2 \%, \mathrm{VOHPO}_{4} \cdot 0.5 \mathrm{H}_{2} \mathrm{O}: 5.7 \%$, and $\mathrm{VOPO}_{4} \cdot 2 \mathrm{H}_{2} \mathrm{O}: 6.4 \%$ ). The carbon balances were $>98 \%$. (c) Reaction pathway for the aerobic oxidation of ethyl lactate on the VPO catalysts. (d) Mass-specific activity for pyruvate formation over VPO catalysts in the temperature range $250-325{ }^{\circ} \mathrm{C}$. (e) Comparisons of the area-specific production rate of pyruvate over $2 \mathrm{D} \beta$-VOPO $\mathrm{VO}_{4}$ nanosheets and $(\mathrm{VO})_{2} \mathrm{P}_{2} \mathrm{O}_{7}$. (f) Stability test of the $2 \mathrm{D} \beta$ - $\mathrm{VOPO}_{4}$ nanosheets under optimized conditions (WHSV $=3 \mathrm{~h}^{-1}$ and $\mathrm{T}=300{ }^{\circ} \mathrm{C}$ ).

\section{Self-Exfoliated Synthesis of Other Transition Metal Phosphate Nanolayers for Catalytic Aerobic Oxidation of Ethyl Lactate to Ethyl Pyruvate. Based on this "self-} exfoliated" synthesis protocol, we successfully made V-, Ni-, Co-, and Fe-based phosphates (see the experimental section in the Supporting Information for details). These desired fewlayer nanosheets with thicknesses of 2-6 $\mathrm{nm}$ were confirmed by HRTEM and AFM analyses (Figures $5 a-c$ and S11). The combination of XRD, SEM, and EDX analyses showed that these phosphates have lamellar layered morphologies with high crystallinity, purity, and uniformity (Figures S12 and S13 and Tables S3-S5, in the Supporting Information). Thus, our synthesis method is general, facile, and scalable via a two-step process (hydrothermal and calcination treatment).

All the PTA-derived phosphate nanosheets were then tested in the vapor-phase aerobic oxidation of ethyl lactate with air at different reaction temperatures $\left(300,325\right.$, and $\left.350{ }^{\circ} \mathrm{C}\right)$. As shown in Figure 6a, control experiments confirmed that $\mathrm{Ni}$ and Co showed some conversion but selectivity to ethyl pyruvate was low, owing to the hydrolysis of ethyl pyruvate on Co- and Ni-based phosphate. ${ }^{36}$ Intriguingly, $\mathrm{VOPO}_{4}$ nanosheets exhibited the best catalytic performance among all the phosphate catalysts tested in this study, giving a remarkably high activity and selectivity. To better understand this, the apparent activation energies $\left(E_{\mathrm{a}}\right)$ were calculated based on Arrhenius plots (Figure $6 \mathrm{~b}$ ), from the data collected below $15 \%$ ethyl lactate conversion. The corresponding $E_{\mathrm{a}}$ value for $\mathrm{VOPO}_{4}(35 \mathrm{~kJ} / \mathrm{mol})$ is much smaller than that for other phosphates: $\mathrm{FePO}_{4}(83 \mathrm{~kJ} / \mathrm{mol}), \mathrm{CoPO}_{4}(102 \mathrm{~kJ} / \mathrm{mol})$, and $\mathrm{NiPO}_{4}(114 \mathrm{~kJ} / \mathrm{mol})$. This result confirmed that $\mathrm{VOPO}_{4}$ is intrinsically more active for ethyl lactate oxidation.

Comparisons of Catalytic Efficiency of Various Vanadium Phosphorus Oxides for Aerobic Oxidation to Ethyl Lactate. Olier et al. reported that all vanadium phosphorus oxides (VPO) can be hydrated except for $\beta$ $\mathrm{VOPO}_{4}$, owing to its highly stable structure. ${ }^{38}$ This is consistent with our XPS measurements (Figure 4c), where no surface-chemisorbed water was detected $(\sim 533 \mathrm{eV})$. As a result, the competing hydrolysis is suppressed, which may explain why the $\beta-\mathrm{VOPO}_{4}$ nanosheets gave such high selectivity to pyruvate compared with other metal phosphate catalysts.

To test this, we prepared a series of bulk VPO catalysts for comparison with our nanosheets: vanadyl pyrophosphate 
$\left[(\mathrm{VO})_{2} \mathrm{P}_{2} \mathrm{O}_{7}\right]$, vanadyl phosphate dihydrate $\left(\mathrm{VOPO}_{4} \cdot 2 \mathrm{H}_{2} \mathrm{O}\right)$, and vanadyl hydrogen phosphate hemihydrate $\left(\mathrm{VOHPO}_{4}\right.$. $0.5 \mathrm{H}_{2} \mathrm{O}$, see the Supporting Information for full experimental details). Their crystalline structures were confirmed by XRD and Raman spectroscopy (Figures S14 and S15). ${ }^{39,40}$ Figure 7a shows the selectivity-conversion plots. All the VPO catalysts were active in lactate-to-pyruvate reaction. Interestingly, $\beta$ $\mathrm{VOPO}_{4}$ nanosheets showed the highest ethyl pyruvate selectivity, reaching over $90 \%$ at an ethyl lactate conversion of $\sim 25 \%$. Even at a high ethyl lactate conversion of $\sim 80 \%$, the selectivity is as high as $80 \%$ compared with $\sim 60 \%$ for $(\mathrm{VO})_{2} \mathrm{P}_{2} \mathrm{O}_{7}$. Control experiments were performed at a steadystate conversion of $\sim 6 \%$ for all the tested catalysts (the carbon balances were $>98 \%$ ) to better differentiate the influence of the VPO phases on product selectivity. As shown in Figure $7 \mathrm{~b}, \beta$ VOPO $_{4}$ nanosheets gave over $99 \%$ selectivity to ethyl pyruvate, while a series of byproducts were detected on other three VPO catalysts, such as acetaldehyde, ethanol, acetic acid, ethyl acetate, and $\mathrm{CO}_{x}$. This indicates that except for the $\beta$-phase, the VPO catalysts undergo the competing overoxidation, hydrolysis, decarbonylation, and decarboxylation (see Figure 7c). The byproduct distribution is different among different catalysts. $\mathrm{VOHPO}_{4} \cdot 0.5 \mathrm{H}_{2} \mathrm{O}$ and $\mathrm{VOPO}_{4} \cdot 2 \mathrm{H}_{2} \mathrm{O}$ gave higher selectivity to ethanol than $(\mathrm{VO})_{2} \mathrm{P}_{2} \mathrm{O}_{7}$, owing to the hydrolysis of ester on their hydrated surfaces.

We also compared the mass-specific activity (calculated as grams of pyruvate produced per gram of the catalyst per hour) over VPO catalysts at different temperatures (Figure $7 \mathrm{~d}$ ). Our $\beta-\mathrm{VOPO}_{4}$ catalyst outperformed the classical phosphates, especially at high reaction temperatures over $300{ }^{\circ} \mathrm{C}$. Moreover, layered $\beta-\mathrm{VOPO}_{4}$ and $(\mathrm{VO})_{2} \mathrm{P}_{2} \mathrm{O}_{7}$ gave similar specific Brunauer-Emmett-Teller areas of 33 and $25 \mathrm{~m}^{2} / \mathrm{g}$, respectively, much higher than $\mathrm{VOHPO}_{4} \cdot 0.5 \mathrm{H}_{2} \mathrm{O}\left(16 \mathrm{~m}^{2} / \mathrm{g}\right)$, $\mathrm{VOPO}_{4} \cdot 2 \mathrm{H}_{2} \mathrm{O}\left(9 \mathrm{~m}^{2} / \mathrm{g}\right)$. We then plotted the area-specific catalytic rates for pyruvate production over $\beta$-VOPO $\mathrm{VO}_{4}$ and $(\mathrm{VO})_{2} \mathrm{P}_{2} \mathrm{O}_{7}$ catalysts. As shown in Figure $7 \mathrm{e}$, the area-specific activity for $\beta$ - $\mathrm{VOPO}_{4}$ nanosheets is almost twice higher than that for $(\mathrm{VO})_{2} \mathrm{P}_{2} \mathrm{O}_{7}$ at $300{ }^{\circ} \mathrm{C}$. The stability and regenerability are key factors for a heterogenous catalyst in its practical application. We tested the stability of our $\beta$-VOPO $\mathrm{V}_{4}$ nanosheets under optimized conditions (WHSV $=3 \mathrm{~h}^{-1}, T=300$ ${ }^{\circ} \mathrm{C}$, see Table S6). As shown in Figure $7 \mathrm{f}$, this catalyst is highly stable, with a steady-state conversion of $\sim 90 \%$ (over $80 \%$ selectivity) for at least $80 \mathrm{~h}$ without significant loss of activity. We also used the same catalyst bed for a series of testing studies, and for this, the catalyst was cleaned and regenerated by simply passing air at $500{ }^{\circ} \mathrm{C}$ for $2 \mathrm{~h}$ and switching off the ethyl lactate feed. The XRD, TEM, and XPS analyses further confirmed that the structure was well preserved after multiple regenerations (Figures S16-S18 in the Supporting Information). Most of the 2D nanosheets are still far from commercialization because their cost is a problem to scaleup. Our $2 \mathrm{D} \beta$ - $\mathrm{VOPO}_{4}$ nanosheets are promising in this regard because they can be readily achieved from inexpensive starting materials such as $\mathrm{VOSO}_{4}$ and PTA. $\mathrm{VOSO}_{4}$ is a byproduct of crude oil refining (ca. 2000-5000 \$/ton), and PTA is a renewable inexpensive plant-based acid (ca. $6500 \$ /$ ton). ${ }^{41}$ The metal salts are also cheap; therefore, these nanosheets are industrially viable catalysts cost-wise as well.

\section{CONCLUSIONS}

We report the synthesis of $2 \mathrm{D}$ ultrathin phosphate nanosheets by a new template-free "self-exfoliated" strategy using renew- able PTA. PTA acts as a strong chelating agent, but can also be carbonized in situ into carbon templates, which are responsible for the precisely controlled few-layer nanosheets. Application of this method to VPO produces $\beta$-VOPO ${ }_{4}$ ultrathin nanosheets, which expose abundant $\mathrm{V}^{4+} / \mathrm{V}^{5+}$ redox sites and oxygen vacancies. Importantly, $\beta$-VOPO $\mathrm{VO}_{4}$ does not get hydrated, thereby reducing the competing hydrolysis by water byproducts. These features result in a superior catalytic activity and selectivity in the aerobic oxidation of ethyl lactate to ethyl pyruvate compared to the classical VPO. The inexpensive $\beta$ - $\mathrm{VOPO}_{4}$ nanosheets show good long-term stability and facile recovery. These nanosheets are not only among the best heterogeneous catalysts for the vapor-phase oxidation of lactate to pyruvate, they also show for the first time that the "inert" $\beta$-VOPO ${ }_{4}$ phase can be an efficient oxidation catalyst under the right conditions. Note that this is a general synthesis method, giving access to various metal phosphate nanosheets, such as $\mathrm{Ni}$, Co, and Fe. Therefore, this work opens a new avenue for the synthesis of new transition metal phosphate nanosheets for catalysis and other applications.

\section{ASSOCIATED CONTENT}

\section{Supporting Information}

The Supporting Information is available free of charge at https://pubs.acs.org/doi/10.1021/acscatal.9b04452.

Experimental procedures; additional characterization data of vanadyl phosphate catalysts including XRD patterns, nitrogen adsorption-desorption isotherms, SEM/TEM/AFM images, EDX spectra, XPS spectra, PALS spectra, and Raman spectra; and results of reaction parameters on aerobic oxidation of ethyl lactate with air (PDF)

\section{AUTHOR INFORMATION}

\section{Corresponding Author}

N. Raveendran Shiju - Van 't Hoff Institute for Molecular

Sciences, University of Amsterdam, 1098 XH Amsterdam, The Netherlands; 이이.org/0000-0001-7943-5864;

Email:n.r.shiju@uva.nl

\section{Authors}

Wei Zhang - Van 't Hoff Institute for Molecular Sciences, University of Amsterdam, 1098 XH Amsterdam, The

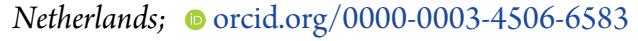

Paula Oulego - Department of Chemical and Environmental Engineering, University of Oviedo, E-33071 Oviedo, Spain

Sandeep K. Sharma - Radiochemistry Division, Bhabha Atomic Research Centre, 400085 Mumbai, India; 이이.org/00000002-9285-3793

Xiu-Lin Yang - Physical Sciences and Engineering Division, King Abdullah University of Science and Technology, 23955-6900 Thuwal, Kingdom of Saudi Arabia; (1) orcid.org/0000-00032642-4963

Lain-Jong Li - Physical Sciences and Engineering Division, King Abdullah University of Science and Technology, 23955-6900 Thuwal, Kingdom of Saudi Arabia; (1) orcid.org/0000-00024059-7783

Gadi Rothenberg - Van 't Hoff Institute for Molecular Sciences, University of Amsterdam, 1098 XH Amsterdam, The Netherlands

Complete contact information is available at: 
https://pubs.acs.org/10.1021/acscatal.9b04452

\section{Notes}

The authors declare no competing financial interest.

\section{ACKNOWLEDGMENTS}

W.Z. thanks the China Scholarship Council (201506140058) for a PhD fellowship. P.O. thanks the Spanish Ministry of Economy and Competitiveness (MINECO) (Project CTM2015-63864-R) and the European Union (FEDER) for funding. P.O. also thanks the access and technical assistance from the Scientific-Technical Services of the University of Oviedo. This work is part of the Research Priority Area Sustainable Chemistry of the University of Amsterdam, http:// suschem.uva.nl.

\section{REFERENCES}

(1) Chhowalla, M.; Shin, H. S.; Eda, G.; Li, L.-J.; Loh, K. P.; Zhang, $\mathrm{H}$. The chemistry of two-dimensional layered transition metal dichalcogenide nanosheets. Nat. Chem. 2013, 5, 263-275.

(2) Ling, T.; Wang, J.-J.; Zhang, H.; Song, S.-T.; Zhou, Y.-Z.; Zhao, J.; Du, X.-W. Freestanding Ultrathin Metallic Nanosheets: Materials, Synthesis, and Applications. Adv. Mater. 2015, 27, 5396-5402. Gitis, V.; Chung, S.-H.; Shiju, N. R. Conversion of furfuryl alcohol into butyl levulinate with graphite oxide and reduced graphite oxide. FlatChem 2018, 10, 39.

(3) Hong, J.; Jin, C.; Yuan, J.; Zhang, Z. Atomic Defects in TwoDimensional Materials: From Single-Atom Spectroscopy to Functionalities in Opto-/Electronics, Nanomagnetism, and Catalysis. Adv. Mater. 2017, 29, 1606434.

(4) Zhang, B.; Wang, L.; Zhang, Y.; Ding, Y.; Bi, Y. Ultrathin FeOOH Nanolayers with Rich Oxygen Vacancies on BiVO4 Photoanodes for Efficient Water Oxidation. Angew. Chem., Int. Ed. 2018, 57, 2248-2252.

(5) Xiong, P.; Ma, R.; Sakai, N.; Sasaki, T. Genuine Unilamellar Metal Oxide Nanosheets Confined in a Superlattice-like Structure for Superior Energy Storage. ACS Nano 2018, 12, 1768-1777.

(6) Ng, W. H. K.; Gnanakumar, E. S.; Batyrev, E.; Sharma, S. K.; Pujari, P. K.; Greer, H. F.; Zhou, W.; Sakidja, R.; Rothenberg, G.; Barsoum, M. W.; Shiju, N. R. The Ti3 AlC2 MAX Phase as an Efficient Catalyst for Oxidative Dehydrogenation of n-Butane. Angew. Chem., Int. Ed. 2018, 57, 1485-1490.

(7) Yang, W.; Zhang, X.; Xie, Y. Advances and challenges in chemistry of two-dimensional nanosheets. Nano Today 2016, 11, 793-816.

(8) Geim, A. K.; Grigorieva, I. V. Van der Waals heterostructures. Nature 2013, 499, 419.

(9) Di, J.; Xia, J.; Li, H.; Liu, Z. Freestanding atomically-thin twodimensional materials beyond graphene meeting photocatalysis: Opportunities and challenges. Nano Energy 2017, 35, 79-91.

(10) Zhu, W.; Gao, X.; Li, Q.; Li, H.; Chao, Y.; Li, M.; Mahurin, S. M.; Li, H.; Zhu, H.; Dai, S. Controlled Gas Exfoliation of Boron Nitride into Few-Layered Nanosheets. Angew. Chem., Int. Ed. 2016, 55, 10766-10770.

(11) Huang, X.; Li, S.; Huang, Y.; Wu, S.; Zhou, X.; Li, S.; Gan, C. L.; Boey, F.; Mirkin, C. A.; Zhang, H. Synthesis of hexagonal closepacked gold nanostructures. Nat. Commun. 2011, 2, 292.

(12) Cheng, W.; He, J.; Yao, T.; Sun, Z.; Jiang, Y.; Liu, Q.; Jiang, S.; $\mathrm{Hu}$, F.; Xie, Z.; He, B.; Yan, W.; Wei, S. Half-Unit-Cell $\alpha-\mathrm{Fe}_{2} \mathrm{O}_{3}$ Semiconductor Nanosheets with Intrinsic and Robust Ferromagnetism. J. Am. Chem. Soc. 2014, 136, 10393-10398.

(13) Wang, J.; Xu, Y.; Ding, B.; Chang, Z.; Zhang, X.; Yamauchi, Y.; Wu, K. C.-W. Confined Self-Assembly in Two-Dimensional Interlayer Space: Monolayered Mesoporous Carbon Nanosheets with In-Plane Orderly Arranged Mesopores and High Graphitized Framework. Angew. Chem., Int. Ed. 2018, 57, 2894-2898.
(14) Sun, Z.; Liao, T.; Dou, Y.; Hwang, S. M.; Park, M.-S.; Jiang, L.; Kim, J. H.; Dou, S. X. Generalized self-assembly of scalable twodimensional transition metal oxide nanosheets. Nat. Commun. 2014, 5, 3813 .

(15) Schliehe, C.; Juarez, B. H.; Pelletier, M.; Jander, S.; Greshnykh, D.; Nagel, M.; Meyer, A.; Foerster, S.; Kornowski, A.; Klinke, C.; Weller, H. Ultrathin $\mathrm{PbS}$ Sheets by Two-Dimensional Oriented Attachment. Science 2010, 329, 550-553.

(16) Son, J. S.; Wen, X.-D.; Joo, J.; Chae, J.; Baek, S.-i.; Park, K.; Kim, J. H.; An, K.; Yu, J. H.; Kwon, S. G.; Choi, S.-H.; Wang, Z.; Kim, Y.-W.; Kuk, Y.; Hoffmann, R.; Hyeon, T. Large-Scale Soft Colloidal Template Synthesis of $1.4 \mathrm{~nm}$ Thick CdSe Nanosheets. Angew. Chem., Int. Ed. 2009, 48, 6861-6864.

(17) Wang, F.; Wang, Z.; Shifa, T. A.; Wen, Y.; Wang, F.; Zhan, X.; Wang, Q.; Xu, K.; Huang, Y.; Yin, L.; Jiang, C.; He, J. TwoDimensional Non-Layered Materials: Synthesis, Properties and Applications. Adv. Funct. Mater. 2017, 27, 1603254.

(18) Dou, Y.; Zhang, L.; Xu, X.; Sun, Z.; Liao, T.; Dou, S. X. Atomically thin non-layered nanomaterials for energy storage and conversion. Chem. Soc. Rev. 2017, 46, 7338-7373.

(19) Centi, G.; Trifiro, F.; Ebner, J. R.; Franchetti, V. M. Mechanistic aspects of maleic anhydride synthesis from $\mathrm{C} 4$ hydrocarbons over phosphorus vanadium oxide. Chem. Rev. 1988, 88, 5580.

(20) Weng, W.; Al Otaibi, R.; Alhumaimess, M.; Conte, M.; Bartley, J. K.; Dummer, N. F.; Hutchings, G. J.; Kiely, C. J. Controlling vanadium phosphate catalyst precursor morphology by adding alkane solvents in the reduction step of $\mathrm{VOPO}_{4} \cdot 2 \mathrm{H}_{2} \mathrm{O}$ to $\mathrm{VOHPO}_{4} \cdot 0.5 \mathrm{H}_{2} \mathrm{O}$. J. Mater. Chem. 2011, 21, 16136-16146.

(21) Centi, G. Vanadyl Pyrophosphate - A Critical Overview. Catal. Today 1993, 16, 5-26.

(22) Coulston, G. W.; Bare, S. R.; Kung, H.; Birkeland, K.; Bethke, G. K.; Harlow, R.; Herron, N.; Lee, P. L. The Kinetic Significance of $\mathrm{V}^{5+}$ in n-Butane Oxidation Catalyzed by Vanadium Phosphates. Science 1997, 275, 191-193.

(23) Hutchings, G. J.; Desmartin-Chomel, A.; Olier, R.; Volta, J.-C. Role of the product in the transformation of a catalyst to its active state. Nature 1994, 368, 41.

(24) Lashier, M.; Schrader, G. L. Reactive lattice oxygen sites for C4 hydrocarbon selective oxidation over $\beta$-VOPO ${ }_{4}$ J. Catal. 1991, 128 , $113-125$.

(25) Gopal, R.; Calvo, C. Crystal structure of $\beta \mathrm{VPO}_{5}$. J. Solid State Chem. 1972, 5, 432-435.

(26) Willinger, M. G.; Su, D. S.; Schlögl, R. Electronic structure of $\beta$ $\mathrm{VOPO}_{4}$. Phys. Rev. B: Condens. Matter Mater. Phys. 2005, 71, 155118.

(27) Eichelbaum, M.; Hävecker, M.; Heine, C.; Karpov, A.; Dobner, C.-K.; Rosowski, F.; Trunschke, A.; Schlögl, R. The Intimate Relationship between Bulk Electronic Conductivity and Selectivity in the Catalytic Oxidation of n-Butane. Angew. Chem., Int. Ed. 2012, $51,6246-6250$.

(28) Wu, C.; Lu, X.; Peng, L.; Xu, K.; Peng, X.; Huang, J.; Yu, G.; Xie, Y. Two-dimensional vanadyl phosphate ultrathin nanosheets for high energy density and flexible pseudocapacitors. Nat. Commun. 2013, 4, 2431.

(29) Zhang, Y.; Zhang, X.; Ling, Y.; Li, F.; Bond, A. M.; Zhang, J. Controllable synthesis of few-layer bismuth subcarbonate by electrochemical exfoliation for enhanced $\mathrm{CO}_{2}$ reduction performance. Angew. Chem., Int. Ed. 2018, 57, 13283-13287.

(30) Beerthuis, R.; Rothenberg, G.; Shiju, N. R. Catalytic routes towards acrylic acid, adipic acid and $\varepsilon$-caprolactam starting from biorenewables. Green Chem. 2015, 17, 1341-1361.

(31) Xu, P.; Qiu, J.; Gao, C.; Ma, C. Biotechnological routes to pyruvate production. J. Biosci. Bioeng. 2008, 105, 169-175.

(32) Sugiyama, S.; Kikumoto, T.; Tanaka, H.; Nakagawa, K.; Sotowa, K.-I.; Maehara, K.; Himeno, Y.; Ninomiya, W. Enhancement of Catalytic Activity on $\mathrm{Pd} / \mathrm{C}$ and $\mathrm{Te}-\mathrm{Pd} / \mathrm{C}$ During the Oxidative Dehydrogenation of Sodium Lactate to Pyruvate in an Aqueous Phase Under Pressurized Oxygen. Catal. Lett. 2009, 131, 129-134. 
(33) Zhang, W.; Innocenti, G.; Ferbinteanu, M.; Ramos-Fernandez, E. V.; Sepulveda-Escribano, A.; Wu, H.; Cavani, F.; Rothenberg, G.; Shiju, N. R. Understanding the oxidative dehydrogenation of ethyl lactate to ethyl pyruvate over vanadia/titania catalysts. Catal. Sci. Technol. 2018, 8, 3737-3747.

(34) Zhang, W.; Ensing, B.; Rothenberg, G.; Raveendran Shiju, N. Designing effective solid catalysts for biomass conversion: Aerobic oxidation of ethyl lactate to ethyl pyruvate. Green Chem. 2018, 20, 1866-1873.

(35) Zhang, W.; Oulego, P.; Slot, T. K.; Rothenberg, G.; Shiju, N. R. Selective Aerobic Oxidation of Lactate to Pyruvate Catalyzed by Vanadium-Nitrogen-Doped Carbon Nanosheets. ChemCatChem 2019, 11, 3381-3387.

(36) Zhang, W.; Innocenti, G.; Oulego, P.; Gitis, V.; Wu, H.; Ensing, B.; Cavani, F.; Rothenberg, G.; Shiju, N. R. Highly selective oxidation of ethyl lactate to ethyl pyruvate catalysed by mesoporous vanadiatitania. ACS Catal. 2018, 8, 2365-2374.

(37) Majjane, A.; Chahine, A.; Et-tabirou, M.; Echchahed, B.; Do, T.-O.; Breen, P. M. X-ray photoelectron spectroscopy (XPS) and FTIR studies of vanadium barium phosphate glasses. Mater. Chem. Phys. 2014, 143, 779-787.

(38) Benabdelouahab, G. F.; Volta, J. C.; Olier, R. New Insights into VOPO4 Phases Through Their Hydration. J. Catal. 1994, 148, 334340.

(39) Li, X.; Ko, J.; Zhang, Y. Highly Efficient Gas-Phase Oxidation of Renewable Furfural to Maleic Anhydride over Plate Vanadium Phosphorus Oxide Catalyst. ChemSusChem 2018, 11, 612-618.

(40) Wang, F.; Dubois, J.-L.; Ueda, W. Catalytic dehydration of glycerol over vanadium phosphate oxides in the presence of molecular oxygen. J. Catal. 2009, 268, 260-267.

(41) Samotus, B.; Schwimmer, S. Phytic Acid as a Phosphorus Reservoir in the Developing Potato Tuber. Nature 1962, 194, 578. 